\title{
A PALAVRA PROFERIDA NO TEMPO: EXPERIÊNCIA TEMPORAL EM A PAIXÃO SEGUNDO G.H.
}

\author{
THE WORD UTTERED IN THE TIME: TEMPORAL \\ EXPERIENCE IN A PAIXÃO SEGUNDO G.H.
}

\section{Anderson Luiz Teixeira Pereira ${ }^{1}$ Sílvio Augusto de Oliveira Holanda ${ }^{2}$}

\begin{abstract}
Resumo: $\mathrm{O}$ trabalho propõe analisar o tempo, tanto como categoria formal da narrativa quanto aspecto temático do universo ficcional, em A paixão segundo G.H. (1964), de Clarice Lispector (1920-1977). Por meio de um movimento de escritura que faz da narração objeto da própria experiência (RICOEUR, 2010, v. 2), a autora modernista brasileira problematiza a composição do romance, ao mesmo tempo que põe em jogo a matéria ali narrada. G.H., narradora e única personagem da narrativa, após viver uma crise individual, por meio da linguagem, busca alcançar uma compreensão para sua existência. Em outros termos, ao passo que a personagem profere a palavra, descerra-se o limite temporal da narração, anulam-se as fronteiras entre passado, presente e futuro, e o tempo torna-se um contínuo (BERGSON, 1988), que, já no nível da estrutura, se manifesta numa escrita que acompanha a temporalidade do próprio sujeito que é tempo (HEIDEGGER, 2008).
\end{abstract}

Palavras-chave: Tempo; narrativa moderna; Clarice Lispector.

Abstract: This paper is a study about time, both as narrative category and as fictional universe theme, in A paixão segundo G.H. (1964), by Clarice Lispector (1920-1977). By means of a movement of writing that makes the narration the object of one's own experience (RICOEUR, 2010, v.2), the Brazilian modernist author problematizes both the composition of the novel and its plot. G.H., narrator and only character of the novel, after experiences an individual crisis, through the speech, She seeks an understanding for hers existence. In other way, when the character utters the word, the temporal limit of narration is overcame, interrupts the limits between past, present and future and time becomes continuous (BERGSON, 1988) which in the novel structure, Its can be realized in a kind of writing that accompanies the subject's temporality who is in time (HEIDEGGER, 2008).

Keywords: Time; Modern Narrative; Clarice Lispector.

No célebre ensaio "Uma tentativa de renovação" - ainda dos anos em que a crítica literária brasileira ocupava o espaço dos rodapés dos jornais - Antonio Candido, autor do referido texto, afirma, a respeito de Perto do coração selvagem (1943), que "este romance é uma tentativa impressionante de levar a nossa língua canhestra para domínios pouco explorados" (CANDIDO, 1992, p. 97). Assim, a crítica quase profética de Candido assinalava, ainda sem a

\footnotetext{
${ }^{1}$ Mestrado em Letras pela Universidade Federal do Pará. Professor substituto da Universidade Federal do Pará. Email: luizandersson@hotmail.com; http://lattes.cnpq.br/6492927615747023

2 Doutorado em Letras (Teoria Literária e Literatura Comparada) pela Universidade de São Paulo. Professor Associado IV da Universidade Federal do Pará. E-mail: eellip@hotmail.com; http://lattes.cnpq.br/0928175455054278

${ }^{3}$ A título de informação, Antonio Candido já havia escrito esta citação no ensaio "No raiar de Clarice Lispector" primeiro texto crítico a respeito de Perto do coração selvagem. Ver CANDIDO, 1970. p. 125.
} 
certeza de um futuro vindouro, o papel profundamente assombrador que a escritura de Clarice Lispector provocaria posteriormente na recente, à época, Literatura Brasileira Moderna.

Em relação ao debate que este trabalho propõe, Earl Fitz (1989), num interessante ensaio, no qual discute "O lugar de Clarice Lispector na história da Literatura ocidental", afirma que a escritora brasileira se enquadra em três grandes gerações, entre as quais destacamos apenas a tradição fenomenológica, que é o ponto que buscaremos privilegiar na nossa leitura acerca de $A$ paixão segundo G.H.. O intelectual enfatiza que:

Se a busca pela verdade da existência humana e por uma autêntica identidade pessoal é um processo psicológico e temporal quer dizer, uma questão não só do futuro, mas duma combinação orgânica do nosso passado, presente e futuro [...], então é bem possível, sugerem os textos de Clarice Lispector, que a existência humana e a identidade pessoal sejam processos sem fim, metas desejadas, mas nunca atingidas. (FITZ, 1989, p. 34).

Tal especulação nos permite reiterar o fato de que o tempo constitui um aspecto fundamental na obra de Clarice Lispector e tem que ver, certamente, com a sensibilidade da autora para as questões que englobam a modernidade no campo artístico. Desse ponto de vista, podemos afirmar que a temática do tempo é oriunda de uma espécie de tradição da própria Literatura Moderna, que, conforme atestaram, por exemplo, em seus trabalhos sobre a relação entre tempo e literatura, Adam Mendilow (1972), Hans Meyerhoff (1976) e Jean Pouillon (1974), por meio da obra de escritores como Thomas Mann, Proust, Virginia Woolf e James Joyce, a realização de experiências ficcionais que englobam a categoria tempo.

Assim, a trama romanesca clariceana que examinaremos, cuja inclinação abeira a mesma desenvoltura do século XX no que tange às questões do tempo, é um exemplo de obra literária que, mediante um jogo particular, possibilitado pela dimensão poética que a constitui, absorve o tempo como matéria narrativa.

Somando-se a isso, há, por outro lado, conforme assinala Hans MeyerHoff (1976), o fato de que "O espírito moderno está profundamente consciente do tempo como uma condição universal de vida e como um fator inextirpável de nosso conhecimento do homem e da sociedade" (MEYERHOFF, 1976, p. 2), o que nos leva à ideia de que a "emergência do tempo no primeiro plano da consciência moderna reflete-se também na literatura" (MEYERHOFF, 1976, p. 3).

Se nos propuséssemos, por exemplo, delinear um quadro histórico do tempo enquanto categoria intrínseca da narrativa, esse não poderia, de todo modo, ser concebido com base em um ideal ou mesmo poderíamos descrevê-lo como imutável, porque teríamos de admitir que sua concepção depende da maneira como o homem e o próprio artista se relacionam com o mundo. Por mais que a especulação acerca do tempo seja recorrente, a grande parte da história do pensamento humano, ele se particulariza em cada época, obra e estilo de escrita, tornando-se peculiar na literatura moderna, em razão do grande laboratório experimental que foi esse momento literário.

Há, desse modo, a possibilidade de se pensar na dimensão estética do tempo, uma vez que sua compreensão decorre da concepção de mundo que permeia o universo da própria obra. Nesse sentido, é legítimo reconhecer o entrecruzamento da experiência da vida moderna com a experiência do tempo na ficção.

Com base na interpretação da experiência narrada em $A$ paixão segundo G.H. é possívelatestar a ideia de que a modernidade, enquanto época fértil para o desenvolvimento de inúmeras questões, é um momento em que a experiência com o tempo se particulariza, no sentido de abrir um vasto campo de possibilidade para se pensar o sentido de um tempo moderno. 


\section{$1 \mathrm{O}$ relógio quebrado de G.H.}

Um pouco mais de duas décadas após a estreia de Clarice Lispector na cena literária, veio a lume $A$ paixão segundo G.H.. Tratava-se do ponto mais alto do trabalho estético da escritora brasileira, que se impôs à atenção da crítica literária por reverberar o limite da linguagem e instaurar novos significados. Desse modo, o quinto romance clariceano, único narrado em primeira pessoa, é o relato de uma personagem apenas identificada pelas iniciais "G.H.", que vive uma "experiência paradoxal"". Nesse sentido, relega-se a vida organizada, envolvida pelo cotidiano fugaz do mundo moderno e instaura-se um processo de "desaprendizagem das coisas humanas" (NUNES, 1989, p. 81), que permite o rompimento com o "mundo convencional" (GOTLIB, 2011, p. 449), cuja consequência será, conforme as palavras metaforizadas de G.H., o "desabamento de cavernas calcárias subterrâneas, que ruíam sob o peso de camadas arqueológicas estratificadas" (LISPECTOR, 2009, p. 44).

Mircea Eliade, em $O$ mito do eterno retorno, no capítulo segundo, dedicado à regeneração do tempo, postula que "o fato essencial é que em toda parte existe uma concepção de final e de começo, de um período de tempo, baseada na observação dos ritmos cósmicos" (ELIADE, 1992, p. 57).

Tal fato apontado por Eliade, ainda que esteja ligado ao desenvolvimento de um tempo mítico, nos faz retomar a clássica concepção de tempo instituída pela tradição aristotélica de que sua constituição se dá por meio da mensuração do movimento astrológico, conforme reitera Reis (1996) em seu estudo sobre o tempo em Aristóteles.

Nesse sentido, perdurou, por um longo período, a compreensão de que o tempo possuía um caráter apenas objetivo, cuja percepção estaria alheia ao indivíduo. Contudo, esse conhecimento tem sua primeira ruptura radical no século quarto com o pensamento de Santo Agostinho (354-430), que escreve, em determinada passagem do livro XI das Confissões, que"o tempo não é o movimento dos corpos" (AGOSTINHO, 1988, p. 289), discordando da concepção temporal advinda de Aristóteles. Para além desta discordância, o teólogo de Hipona dá um passo mais largo, ao propor, indiretamente, uma nova concepção de tempo, que, ao que parece, está relacionada, em parte, ao conceito de "duração interior" (BERGSON, 1988), por considerar o tempo como um aspecto ligado à percepção humana.

Refletir sobre o tempo na literatura moderna significa reconsiderar e avaliar as concepções que surgiram ao longo da história da humanidade e como elas são manifestadas na concepção de mundo do texto literário. Diante disso, podemos traçar a seguinte pergunta: qual seria uma possível concepção de tempo em $A$ paixão segundo G.H? Ora, importa menos uma resposta do que a reflexão que se pode desenvolver com base nela.

O tempo, no romance clariceano, é propriamente um tempo humano - particular à modernidade - pois, segundo Mendilow (1976, p. 4), "seu significado deve ser buscado somente dentro do contexto desse mundo de experiências ou dentro do contexto de uma vida humana como a soma total dessas experiências". Não se trata da negação do tempo físico ou mesmo da ausência de uma sucessão temporal cronológica. Ocorre que ambos os tempos, objetivo e subjetivo, isto é, interno e externo, estão presentes na trama romanesca de Clarice Lispector. Contudo, a interpretação da temporalidade só é possível quando consideramos a particularidade do tempo vivido e narrado pela protagonista.

É em função disso que a nossa pressuposição consiste em afirmar que a metáfora do

\footnotetext{
${ }^{4}$ Afirmamos ser a experiência vivida por G.H paradoxal de acordo com de Nunes (1989, p. 60), no sentido de que é por meio da perda da aprendizagem humana que a personagem atinge o sentido máximo de sua experiência. Apesar disso, nossa leitura se afasta de Benedito Nunes, que compreende o itinerário de G.H. como um processo místico.
} 
relógio quebrado ${ }^{5}$ significa a instauração da abertura para o tempo vivido, de modo que a linguagem - modus operandi — tensiona figuras temporais como ordem e duração, radicalizando o jogo temporal forjado no âmbito do mundo ficcional. Em outras palavras, nosso enunciado expressa a ideia de que o tempo objetivo, ainda que presente no romance moderno, se encontra suspenso.

Isso justifica o forte apelo da literatura moderna para a experiência subjetiva do tempo, para o deslocamento do centro mimético para a consciência individual e para a fragmentação do sujeito e da estrutura do texto, sendo esta última ratificada na própria conformação de $A$ paixão segundo G.H., que é construída por uma narração fragmentada ${ }^{6}$, que acompanha, em termos metafóricos, a desagregação da própria personagem que narra.

G.H. vivencia um adensamento temporal e, por isso, já não importa a duração dos acontecimentos narrados, porém a atenção recai sobre a própria enunciação. A questão central está assente na necessidade de romper com o sistema que a impedia de alcançar a compreensão do que é de fato viver: "Não posso pôr em palavras qual era o sistema, mas eu vivia num sistema" (LISPECTOR, 2009, p. 160). Quer dizer, esse sistema também tem que ver com a relação da temporalidade, pois para G.H., a ruptura é a possibilidade de uma existência recalcada na reflexão.

O tempo do relógio não é capaz de captar "a quarta dimensão de um tempo-já" parafraseando o interlocutor de Água viva (1973). Desse modo, o tempo marcado pelos relógios entra em desacordo com o sentido do tempo experimentado pela personagem, como relata G.H.: "E inesperadamente as próximas vindouras onze horas da manhã me pareceram um elemento de horror - como o lugar, também o tempo se tornava palpável, eu queria fugir como de dentro de um relógio, e apressei-me desordenadamente.” (LISPECTOR, 2009, p. 49).

O relógio é um dos símbolos fundamentais da relação entre tempo e modernidade, pois sua figura ilustra, de certo modo, o esforço simbólico da sociedade em tentar instrumentalizar e controlar o tempo, que, no final das contas, acaba falhando. A respeito desse artifício, o sociólogo alemão Norbert Elias (1998), cujo trabalho aponta a negação da objetividade do tempo, no sentido de que, para ele, o tempo trata de um elemento social, resultado de um longo processo de aprendizagem, afirma que:

Os relógios não medem o tempo? Se eles permitirem medir alguma coisa não é o tempo invisível, mas algo perfeitamente passível de ser captado, como a duração de um dia de trabalho ou de um eclipse lunar, ou a velocidade de um corredor na prova de cem metros. Os relógios são processos físicos que a sociedade padronizou, decompondo-os em sequências-modelos de recorrência regular, como as horas ou minutos. (ELIAS, 1998, p. 7)

A experiência ficcional no romance de Clarice Lispector propicia o rompimento com o modo convencional de uma narrativa pautada na linearidade e na cronologia, colocando em cheque valores da tradição, como a concepção de que o tempo é um dado físico, mensurável e, sobretudo, uma determinação do real, passível de ser medido pelos artifícios forjados no bojo da vida social moderna.

De enunciado a enunciado, G.H. erra a cronologia dos fatos narrados. Mas errar é a condição preliminar para romper com uma espécie de "organização" humana que esconde a sua

\footnotetext{
${ }^{5}$ É válido assinalar que, em Perto do coração selvagem, a presença material do relógio, que surge já no capítulo de abertura, intitulado "O pai", atinge o simbolismo do rompimento com o tempo físico na narrativa na medida que o “tin-dlen do relógio é silenciado, conforme já observou, em sua dissertação de Mestrado, Marília Cerqueira (2013): "Oriundas da realidade concreta, em certos instantes, as imagens acústicas começam a se distanciar e ficar cada vez mais inaudíveis. A partir daí o relógio para. No entanto, o tempo segue, em fluxo repleto de variações, saltos para frente e para trás, passado e futuro se alternam em aparente desordem, profundos espaços vazios e fragmentações." (CERQUEIRA, 2013, p. 33).

${ }^{6}$ Lembremo-nos de que A paixão segundo G.H. é constituída, não por capítulos, como os romances tradicionais, mas por trinta e três fragmentos.
} 
verdadeira identidade. Lembremo-nos do fato de a protagonista, que sente a necessidade de contar a alguém o que viveu, ao passo que o faz, distrai-se refletindo sobre questões humanas. Como resultado desse conflito entre contar e refletir, tem-se uma confluência de tempos. Nos intervalos, entre a projeção, ora da ação humana, ora da divagação, o jogo temporal reconfigura a realidade vivida, à medida que o tempo se torna apenas a percepção que dele se tem.

O desenvolvimento de um tempo subjetivo permite apontar o fato de que $A$ paixão segundo G.H. é um romance expressivo para a sondagem de uma temporalidade complexa. Isso porque nessa obra há, antes de tudo, a narração de uma experiência humana que atinge o limite da linguagem e, ao mesmo tempo, por meio dela, tenta-se alcançar a compreensão dos próprios fatos relatados. Assim, a linguagem é, enquanto medium, o quepossibilita, a priori, a concretização da narrativa, no sentido de que ela é o elemento que estrutura, articula e configura os diversos blocos temporalmente dispersos, de modo a se elaborar um enredo que funda o seu próprio código, como atesta, por exemplo, a pontuação inusitada que fecha e abre o ciclo romanesco clariceano, bem como por meio da sintaxe inusitada, que acompanha o ritmo de fala de G.H..

A relação entre tempo e linguagem é fundamental no quinto romance de Clarice Lispector. Paul Ricoeur (2010, v. 2, p. 103) assinala que "narrar já é 'refletir sobre' os acontecimentos narrados", fato que ratifica a importância do nosso apontamento. A necessidade de traduzir a experiência do dia anterior - tomado como mote do primeiro fragmento significa não apenas a garantia da materialidade da narração ou, como diria G.H., "salvar o dia de amanhã" (LISPECTOR, 2009, p. 13), mas, principalmente, a reconquista de uma nova identidade ou de um novo modo de ser por meio da palavra.

Nesse contexto, a linguagem estabelece uma ligação entre o tempo da história e o presente da narração, pois ambos, que, a princípio, se encontravam separados,seguem num fluxo contínuo até serem suspensos e não haver separação entre o ontem e o hoje, restando apenas a sensação do "instante-já" ou da "duração interior" bergsoniana: "E terminara, também eu toda imunda, por desembocar através dela para o meu passado que era o meu contínuo presente e meu futuro contínuo" (LISPECTOR, 2009, p. 64).

Essa condensação de tempos é o que viabiliza, ainda, a fragmentação do ser, o qual havia sido "neutralizado pela vida diária" (NUNES, 1989, p. 104). O tempo é substancial para a experiência de G.H., pois sua metafórica "metamorfose" (LISPECTOR, 2009. p. 66) ultimar-seá, à medida que o tempo da narração avança, ou seja, conforme a palavra é proferida, o desfecho é uma nova organização do "amorfo dinâmico da vida" (MENDILOW, 1972, p. 9).

A personagem apenas alcança a consciência de si mediante o exercício da narração como reflexão. É pela palavra narrada que G.H. compreende a sua própria temporalidade, conforme se verifica no seguinte trecho, no qual se destaca o reconhecimento do limite da temporalidade humana: "Minha vida fora tão contínua quanto a morte. A vida é tão contínua que nós a dividimos em etapas, e a uma delas chamamos de morte. Eu sempre estivera em vida, pouco importa que não eu propriamente dita, não isso a que convencionei chamar de eu." (LISPECTOR, 2009, p. 64).

Clarice Lispector aponta o fato de que esse sujeito/personagem moderno vive um apaziguamento da consciência do tempo em função do cotidiano coisificado, o qual apenas é rompido, considerando o contexto do universo literário, conforme também já observou Benedito Nunes (1989), diante da solidão. No geral, essa é a situação na qual G.H. se encontra e apenas por meio dela consegue romper com uma ordem pré-estabelecida que a envolve, como a vida doméstica, e, por fim, aderir a um estado de êxtase reflexivo.

Não há como deixar de referir, dado o contexto da discussão, a sedução que a crítica clariceana teve em aproximar a obra da escritora das questões da temporalidade em Martin Heidegger (2012) e (2008). O filósofo da Floresta Negra, em O conceito de tempo - conferência proferida antes mesmo de ser e tempo (1927) —, após avaliar as concepções de temporalidade tradicionais, conclui que "O tempo, então, seria eu mesmo, e cada qual seria o tempo". 
(HEIDEGGER, 2008, p. 31)

Heidegger confere à existência humana um caráter radicalmente hermenêutico, no sentido de que é na reflexão sobre a vivência, ou melhor, sobre a finitude do dasein, que se encontra a própria abertura para o sentido da existência. É por isso que G.H., em termos heideggerianos, alcança o sentido de sua existência, ao tomar consciência de sua temporalidade quando ela se debruça sobre a finitude do ser — "o ser-aí não é no tempo, ele mesmo é o tempo” (HEIDEGGER, 2008, p. 51). Conforme propôs o filósofo alemão:

O fim do meu ser-aí, a minha morte, não é algo que suspenda um percurso, mas sim uma possibilidade, que o ser-aí de alguma maneira conhece: a sua possibilidade mais extrema, que ele pode captar e de que se pode apropriar de modo iminente. O ser-aí tem em si mesmo a possibilidade de se deparar com a sua morte enquanto a mais extrema das possibilidades de si mesmo. Esta possibilidade extrema de ser é uma certeza, com o carácter de iminência, mas esta certeza, pelo seu lado, caracterizase por uma indeterminabilidade total. (HEIDEGGER, 2008, p. 45)

Foi Benedito Nunes, desde suas primeiras leituras críticas sobre Clarice Lispector, que datam do ano de 1965, até $O$ drama da linguagem (1989), talvez, o estudioso que mais tenha se dedicado à tarefa de apontar a presença da filosofia da existência na escritura de Clarice Lispector. Apesar disso, é válido ressaltar que nossa leitura, apesar de reconhecer pontos tangentes entre a filosofia e a literatura clariceana e do parêntese ora efetuado, não tem o intuito de demonstrar uma concepção de mundo de temática "marcadamente existencial" (NUNES, 1989, p. 100) na obra da autora de Perto do coraşão selvagem (1943) como empreendeu Benedito Nunes.

Fechado o parêntese acima, é importante reiterarmos que $A$ paixão segundo G.H. é um romance que sofre da obsessão do tempo justamente, por ser construído por intermédio da autorreflexão, do fluxo de consciência e da busca pela forma. Com base nesses três aspectos e por meio da palavra poética, afinal, "Será preciso coragem para fazer o que vou fazer: dizer.", como relata G.H. (LISPECTOR, 2009, p. 18), a temporalidade do mundo da obra é contorcida a ponto de a protagonista ser forçada a forjar um tempo ficcional ${ }^{7}$, cujo resultado é uma superestrutura temporal, particular ao romance, que liga passado e presente, o qual pode ser designado como experiencial, pois tem nexo com a durée bergsoniana:

Vou criar o que me aconteceu. Só porque viver não e relatável. Viver não é vivível. Terei que criar sobre a vida. E sem mentir. Criar sim, mentir não. Criar não é imaginação, é correr o grande risco de se ter a realidade.Entender e uma criação, meu único modo. Precisarei com esforço traduzir sinais de telégrafo — traduzir o desconhecido para uma língua que desconheço, e sem sequer entender para que valem os sinais. Falarei nessa linguagem sonâmbula que se eu estivesse acordada não seria linguagem. (LISPECTOR, 2009, p. 19)

Segundo Benedito Nunes (2008, p. 58), a durée "é, para Bergson, o tempo verdadeiro, que a intuição capta no relance da experiência interior libertada da dominância dos fins práticos da ação". Nesse sentido, designamos o tempo em A paixão segundo G.H. como experiencial porque ele transcende o caráter físico e psicológico da própria temporalidade da narrativa. Apesar de a experiência vivida por se situar no "ontem", isto é, no dia anterior ao presente da narração, o esforço da personagem não consiste apenas em relatar a sequência de ações do dia anterior: sentada à mesa do café, decisão de limpar o apartamento, roteiro fracassado da limpeza, deslocamento ao bas-fond, onde estava localizado o quarto de empregada, por onde começaria a limpeza e, finalmente, o confronto com a barata. Eis aí a síntese da ação humana, isto é, da linha cronológica da trama. Entretanto, não é a esse tempo que G.H. se refere quando enfatiza a necessidade de organizar, de algum modo, a experiência informe que vivera no dia anterior:

\footnotetext{
${ }^{7}$ É válido assinalar que, em consonância com os postulados de Paul Ricoeur (2010, v. 2, p. 174), a "experiência fictícia do tempo é apenas o aspecto temporal de uma experiência virtual do ser no mundo proposta pelo texto."
} 
O que vi não é organizável. Mas se eu realmente quiser, agora mesmo, ainda poderei traduzir o que eu soube em termos mais nossos, em termos humanos, e ainda poderei deixar desapercebidas as horas de ontem. Se eu ainda quiser poderei, dentro de nossa linguagem, me perguntar de outro modo o que me aconteceu. (LISPECTOR, 2009, p. 67)

Trata-se, portanto, propriamente do tempo da "duração interior", o qual é iniciado no momento em que G.H. adentra o quarto, que até àquela semana pertencera a sua empregada Janair, que se havia despedido no dia anterior, e adere a uma espécie de esquizofrenia momentânea despertada pelo "fascínio da barata que a repugna e a atrai" (NUNES, 1989, p. 58).

Assim, inicia-se, conforme assinala Benedito Nunes acerca da concepção temporal de Bergson (1988), o reinado de um tempo marcado por "momentos imprecisos, inseparáveis dos estados mutáveis da consciência, que se interpenetram, formam [...] a sucessão pura, interior, irredutível à sucessão no movimento físico, decomponível em intervalos homogêneos exteriores." (NUNES, 2008, p. 58). Isso é vital para a experiência de G.H., pois é nesse estado durativo de um agora contínuo que a personagem se desagrega de sua montagem humana, como se assinala na abertura do romance "------ estou procurando, estou procurando" (LISPECTOR, 2009 , p. 9). É nessa temporalidade inerente ao ser, atingida por meio da ruptura com a realidade externa, que ela se liberta de clausura de uma vida inteira acumulada.

Nesse contexto, é interessante comentar o trabalho de Maria de Oliveira (1994) que, sob uma perspectiva bachelardiana, aponta o desenvolvimento de um tempo verticalizado ${ }^{9} \mathrm{em} A$ paixão segundo G.H.: "No seu arroubo e êxtase G.H. atinge ainda um tempo vertical, que não reconhece o valor do passado e do futuro, mas que se condensa no 'hoje' e no 'agora-já"' (OLIVEIRA, 1994, p. 177). A concepção temporal aventada pela pesquisadora, apesar de ser fundamentada nos postulados de Gaston Bachelard, assemelha-se ao tempo em Bergson (1988) - a durée - e em Santo Agostinho - a distentio. Dessa forma, ratificamos a nossa pressuposição de um tempo experiencial, humanizado, vivido, que é difícil de ser transpassado à materialidade da palavra, impondo à G.H. a tarefa de fazer da experiência do dia anterior uma criação.

É por esse motivo que o tempo da história — matéria do relato de G.H. — é suspenso e deslocado para o tempo do discurso, assim que a personagem inicia o itinerário da narração. Mas mesmo efetuada essa confluência de tempos, ambos são estagnados. A única temporalidade vigente é a do próprio ser, a qual é assegurada pela linguagem, pois esta se dá no tempo. Como afirma a protagonista "A palavra e a forma serão a tábua onde boiarei [...]" (LISPECTOR, 2009, p. 18), ou seja, a palavra e a forma são as únicas garantias palpáveis da temporalidade da experiência de G.H..

Lembremo-nos de que Santo Agostinho, em suas Confissões, já se havia voltado para o fato de que "Ainda que se narre os acontecimentos verídicos já passados, a memória relata não os própriosacontecimentos que já decorreram, mas sim as palavras concebidas pela imagem daqueles fatos" (AGOSTINHO, 1988, p. 282). Dessa forma, a experiência de G.H. pode ser tomada como um ciclo temporal em aberto, cujo ponto de partida se dá no encontro com a barata, que depois daquelas longas horas no quarto da empregada é apaziguado, e é retomado novamente no dia seguinte — já no presente da narração — quando a palavra volta novamente a ser proferida: "Finalmente, meu amor, sucumbi. E tornou-se um agora" (LISPECTOR, 2009, p. 78).

\footnotetext{
8 Aliás, um dos motes reiterado, vez ou outra, por G.H. é o acúmulo de uma vida resultada de um cotidiano arrumado, alienado, que coisifica o sujeito e relega-o da identidade autêntica, da qual as personagens clariceanas, de um modo geral, padecem e sempre estão à procura: “O acúmulo de viver numa superestrutura tornava-se cada vez mais pesado para se sustentar no ar.” (LISPECTOR, 2009, p. 67).

9 Tomamos, para este trabalho, a expressão "tempo verticalizado" como sendo sinônimo de um tempo não cronológico, ou seja, que se qualifica em função de um aspecto de densidade, relacionado ao modo como o indivíduo o percebe em sua vivência.
} 
Chegamos a um dos aspectos fundamentais acerca da temporalidade do romance ora analisado.O agora passa a ser o tempo humanizado da protagonista. A experiência vivida no dia anterior, embora tenha seu referencial no tempo pretérito, se consuma no "agora" do presente narrativo: "São onze horas da manhã no Brasil. É agora.". (LISPECTOR, 2009, p. 79). Cronos é destituído de seu reinado imperioso e o que resta é apenas o agora da experiência, o estar sendo, o processo durativo, o qual é manifestado pelos verbos empregados no gerúndio": "procurando", "tentando", "vivendo", entre outros.

A respeito da questão técnica, podemos considerar que essa temporalidade complexa efetuada a altura de um jogo temporal moderno tem que ver com o fato já sublinhado por Jean Pouillon (1974, p. 117-118) de que "O romancista se propõe a mostrar o tempo tal como foi vivido, ora, ele foi vivido 'no presente' [...]. É com efeito a realidade do presente que faz a cronologia, sem um 'agora' o curso do tempo perde toda consciência". Ora, como demonstramos, no caso do romance clariceano,essa proposição se torna mais radical em virtude de ela ser repassada da forma do texto para a própria matéria narrativa. Transpor o passado para um "agora" não é apenas um esforço técnico de Clarice Lispector, pois isso significa, antes de tudo, já no campo temático, a recomposição da narradora, a qual havia se fragmentada no momento em que ela chega ao estado denominado de "inumano".

É por esse motivo, talvez, que o romance da escritora brasileira modernista seja marcado pelo fluxo de consciência, fato recorrente ao romance moderno e que, segundo nos elucida Meyerhoff (1976, p. 16) “A 'corrente de consciência' significa o que o simbolismo do tempo [...] sempre quis transmitir, isto é, que o tempo experimentado tem a qualidade do fluir". Seguindo a mesma linha de romancistas como Proust, Virginia Woolf e James Joyce, para citarmos apenas alguns nomes, predomina nos escritos de Clarice Lispector a "passagem da introspecção ao primeiro plano da narrativa" (NUNES, 2009, p. 205), que em A paixão segundo G.H., é intensificada pela ausência de uma estrutura de diálogo.

Isso quer dizer tão somente que a subjetividade, que faz do tempo uma propriedade particular do eu, passa a ser o verdadeiro páthos que movimenta a escritura e projeta sua ruptura com o tempo do mundo exterior - o físico. A própria G.H. assinala esse movimento da escritura quando confessa seu desejo de interromper a narrativa introspectiva, que desdobra e transpõe a experiência para a linguagem humana, para "inserir neste difícil relato, por pura diversão e repouso, uma história ótima que ouvi um dia desses sobre o motivo por que um casal se separou" (LISPECTOR, 2009, p. 80).

O labor literário de Clarice Lispector, que se assentou, sobretudo, num trabalho ousado com a linguagem, como já aludido pelos seus críticos, rompe com a tradição do pensamento ocidental. A propósito disso, Silvino Santiago (1997, p. 6), num ensaio intitulado "A aula inaugural de Clarice Lispector", declara que "Quis ela inaugurar uma outra concepção de tempo para o romance". O jogo temporal instaurado no mundo ficcional de sua narrativa beira a uma experiência absurda, no sentido de que, como já ressaltado, se funda um código próprio para dar conta do tempo. Dizemos absurda em decorrência, também, do afastamento e da quebra de um tempo mimético. Ora, se a subjetividade manifestada na introspecção e no ponto de vista em primeira pessoa ocupa o centro privilegiado da ficção clariceana, logo a realidade do mundo ficcional é posta em crise em função de o próprio narrador viver uma crise existencial. O mundo palpável, material e concreto, após a esquizofrenia momentânea que arrebata G.H., desmorona: "ontem, sem aviso, houve o fragor do sólido que subitamente se torna friável numa derrocada." (LISPECTOR, 2009, p. 68).

Pontieri (2001, p. 109-112), ao tratar do problema do tempo na ficção clariceana, assinala o papel fundamental que a relação entre a subjetividade, o tempo e a realidade desempenha no

\footnotetext{
${ }^{10}$ Em relação a isso, como já demonstrou Olga de Sá (1979) a partir de Perto do coração selvagem, a escritura clariceana é marcada pelo uso de verbos no gerúndio, os quais enfatizam a ideia de um tempo fluido, contínuo, conforme apontamos também ser recorrente em A paixão segundo G.H..
} 
mundo ficcional. Isso porque, nas obras de Clarice Lispector, sobretudo no romance que estamos estudando, o fadário da introspecção, que cresce nos momentos de ruptura, desarmoniza o nexo de G.H. com o mundo. Assim, alinhados à compreensão da estudiosa, confirmamos a assertiva do parágrafo anterior acerca de um mundo ficcional, cuja realidade é colocada em crise, por ser a experiência de G.H não somente uma busca por uma compreensão de si, mas principalmente uma desaprendizagem das coisas humanas.

Mas voltemos à questão da temporalidade como o agora, a fim de ultimar o percurso proposto de desdobrar o itinerário-tempo de G.H.. Não pretendemos esboçar os poucos momentos relativos aos processos humanos expressados no romance, pois, como já mencionamos, eles se resumem ao deslocamento da protagonista da sala para o quarto da empregada.

"É que um mundo todo vivo tem a força de um inferno" (LISPECTOR, 2009, p. 22). Naquela manhã, até antes de entrar no quarto, G.H. ainda não havia descoberto a força que o tempo poderia desempenhar na sua existência arrumada. Bastou a brevidade de uma manhã para que a vida inteira da personagem desmoronasse. Presa a um sistema, envolvida por uma vida confortável aparentemente luxuosa e protegida no ponto mais alto do edifício, a mulher descobriria a dura verdade de que: "Perdida no inferno abrasador de um canyon uma mulher luta desesperadamente pela vida"' (LISPECTOR, 2009, p. 22) — frase que G.H. lera há muito tempo numa revista qualquer, mas que só agora lhe fazia sentido.

Diante do silêncio imperioso que dominava o seu apartamento, na medida que G.H. caminha em direção ao quarto, o tempo externo vai esvaziando-se, perdendo a profundidade, até o ponto de se tornar apenas um agora.

Não podemos deixar de assinalar pelo menos dois momentos distintos interpostos entre esse tempo-agora definido pela personagem como uma "continuação de uma ininterrupção" (LISPECTOR, 2009, p. 22). Antes de tudo ter se tornado apenas o agora, G.H. fora um outro ser e, depois da consumação da experiência, ela se torna uma nova criatura. A primeira G.H. é a imagem espelhada de si, isto é, apenas um reflexo oriundo de uma visão que é sempre do outro: “"Como se não fosse eu"” (LISPECTOR, 2009, p. 30). A segunda, que surge após “remorrer”, é uma compreensão nova de si mesma. A personagem tem ciência de que antes fora uma outra que agora já não é mais, fato que se comprova, por exemplo, quando ela reflete com certa clareza sobre o que se sucedera no dia anterior, referindo-se a si mesma em terceira pessoa, utilizando o pronome "ela", que na verdade, alude o que fora no "ontem" e, ao mesmo tempo, reafirma a consciência de que agora é um novo ser.

Nesse sentido, o agora — que é aflorado pela "consciência solitária" (NUNES, 1989, p. 104), afinal, o quarto é a representação simbólica de um extremo afastamento do convívio social — é a única temporalidade do simbólico deserto, onde ela caminha até atingir o ponto máximo de sua experiência: o núcleo da vida, a natureza crua e viva das coisas:

Ontem de manhã — quando saí da sala para o quarto da empregada — nada me fazia supor que eu estava a um passo da descoberta de um império. A um passo de mim. Minha luta mais primária pela vida mais primária ia-se abrir com a tranquila ferocidade devoradora dos animais do deserto. Eu ia me defrontar em mim com um grau de vida tão primeiro que estava próximo do inanimado. No entanto nenhum gesto meu era indicativo de que eu, com os lábios secos pela sede, ia existir. (LISPECTOR, 2009, p. 22)

A tópica do deserto é uma temática importante no desenvolvimento de $A$ paixão segundo G.H., que segundo Nunes (1989, p. 71) "O deserto da vida divina é o silêncio das coisas que a

\footnotetext{
${ }^{11}$ Cabe ressaltar que o deserto referido por G.H., para Benedito Nunes (1989), está relacionado ao sentido místico. Em nossa leitura, tomamos o deserto como uma metáfora da travessia de G.H. pelo itinerário da narração, que busca desdobrar a própria existência.
} 
visão alcança, o silêncio da coisa em sua mudez, a que a palavra nos liga e de que a palavra nos separa.". Esse deserto é instaurado na ruptura de G.H. com o sistema mundano. No momento do confronto com a barata, ao abrir a porta do guarda-roupa, abre-se, do mesmo modo, a passagem para o deserto: "A entrada para este quarto só tinha uma passagem, e estreita: pela barata” (LISPECTOR, 2009, p. 58) e, em outro momento, acrescenta G.H.: "A passagem estreita fora pela barata difícil” (LISPECTOR, 2009, p.64). Entretanto, como bem observou Benedito Nunes:

Não é sem resistência que G.H. cede à atração dessa realidade impessoal de que tem, por um contato físico de todo o seu corpo, um conhecimento participado. Até sucumbir ao êxtase que a integra à exterioridade da matéria viva, G.H. está dividida entre o desejo de seguir o apelo do mundo abismal e inumano onde vai perder-se, e a vontade de conservar a sua individualidade humana. (NUNES, 1989, p. 59)

Lembrem-nos de que, apesar de estar fisicamente dentro do cômodo quase quadrilátero, G.H. tem a sensação de estar do lado de fora: "Mesmo dentro dele, eu continuava de algum modo do lado de fora. Como se ele não tivesse bastante profundidade para me caber e deixasse pedaços meus no corredor [...]" (LISPECTOR, 2009, p. 44). Em outro texto de Benedito Nunes (1988), num dos comentários à edição crítica do A paixão segundo G.H., o estudioso chama atenção, ainda, para o prenúncio do deserto, o qual estaria implícito na imagem da poeira que encobria o quarto da empregada, que é também o elemento de ânimo para a limpeza pretendida pela personagem.

Diante da "barata grossa", a mulher seria capturada pela eternidade daquele deserto. Mas como assinala Olga de Sá (1979, p. 84) "a eternidade não é algo abstrato e frio, mas um momento concreto e singular, um agora permanente [...]". É esse agora permanente que é iniciado na travessia pelo deserto: "Mas eu estava no deserto. E não é só num ápice de um oásis que é agora: agora também é no deserto [...]" (LISPECTOR, 2009, p. 79).

Não importaria a presença do relógio, assim como bem apontou Paul Ricoeur (2010, v. 2) acerca das badaladas do Big Ben em Mrs. Dalloway (1925), de Virginia Woolf. Em A paixão segundo G.H.,o tempo cronológico, a princípio, marcado, por exemplo, pelo sol que invadia o quarto da empregada pela janela, indicando a mensuração de um tempo físico, é dissimulado em virtude da instauração da eternidade como sentimento de tempo.

Como dizíamos, a travessia pelo deserto confere à G.H. a realidade temporal sui generis de sua experiência. Esse tempo-já é o agente da transformação da personagem. À medida que ele se sucede, G.H. vai perdendo suas finas cascas, pois, assim como a barata, ela também era constituída de finas camadas, conforme ela mesma se compara.

A imagem mitificada do deserto suscita o neutro da barata, a matéria viva, a glória da natureza despida, o atingimento do mundo inumano, o desmascaramento do ser, a queda da moral, a ausência de forma e de organização, a perda da terceira perna, a existência amorfa. Assim, nessa travessia imperiosa, dolorosa, que culmina na descoberta da verdade sobre si, finalizamos esta análise acerca do tempo moderno e complexo em $A$ paixão segundo G.H.. Conforme buscamos enfatizar, a linguagem, que é um dos pontos cruciais da narrativa, possibilita a absorção do tempo como parte da própria experiência narrada, pois a palavra poética é proferida no tempo.

Analisar o tempo na obra de Clarice Lispector, acompanhando o movimento que vai da estrutura à matéria da narrativa, significa enfatizar o trabalho artístico dessa escritora, que explorou a linguagem poética para além do limite do possível e promoveu uma fissura no próprio sentido da palavra tempo. 


\section{Referências}

AgOSTINHO, Santo. Livro XI. In: Confissões. Trad. J. Oliveira Santos; A. Ambrósio de Pina. Petrópolis: Vozes, 1988. p. 266-296.

BERGSON, Henri. Ensaio sobre os dados imediatos da consciência. Trad. João da Silva Gama. Lisboa: Edições 70, 1988.

CANDIDO, Antonio. No raiar de Clarice Lispector. In: Vários escritos. São Paulo: Duas Cidades. 1970. p. 125-131.

p. 93-102.

. Uma tentativa de renovação. In: Brigada Ligeira e outros escritos. São Paulo: UNESP. 1992,

CERQUEIRA, Marilia Danielle Santos. Confluências temporais em Clarice Lispector: análise de Uma aprendizagem e Água viva. 2013. 109 p. Dissertação (Mestrado em Literatura e Cultura) Universidade Federal da Bahia, Salvador.

ELIADE, Mircea. Mito do eterno retorno. Trad. José A. Ceschin. São Paulo: Mercuryo, 1992.

FIRTZ, Earl. O lugar de Clarice Lispector na história da literatura ocidental: uma avaliação comparativa.Remate de Males, Campinas, n. 9, p. 31-37, 1989.

GOTLIB, Nádia. Clarice uma vida que se conta. São Paulo: Edusp, 2011.

HEIDEGGER, Martin. O conceito de tempo. Trad. Irene Borges-Duarte. Lisboa: Fim do século, 2008.

. Ser e tempo. Trad. Fausto Castilho. São Paulo: UNICAMP; Rio de Janeiro: Vozes, 2012.

LISPECTOR, Clarice. Água viva. Rio de Janeiro: Rocco, 1998.

A paixão segundo G.H. Ed. crítica organizada por Benedito Nunes. Brasília: CNPq, 1988.

A paixão segundo G.H. Rio de Janeiro: Rocco, 2009.

Perto do coraça selvagem. Rio de Janeiro: Rocco: 1988.

MENDILOW, Adam. O tempo e o romance. Trad. Flávio Wolf. Porto Alegre: Globo, 1972.

MEYERHOFF, Hans. O tempo na literatura. Trad. Myriam Campello. São Paulo: McGraw-Hill, 1976.

NORBERT, Elias. Sobre o tempo. Trad. Vera Ribeiro. Rio de Janeiro: Jorge Zahar Editor, 1998.

NUNES, Benedito. A clave do poético. São Paulo: Companhia das Letras, 2009.

.Narrativa histórica e narrativa ficcional. In: RIEDEL, Dirce Côtes (Org.). Narrativa: ficção e história. Rio de Janeiro: Imago, 1988. p. 9-35.

O drama da Linguagem: uma leitura de Clarice Lispector. São Paulo: Ática, 1989.

- O tempo na narrativa. São Paulo: Ática, 2008.

OLIVEIRA, Maria Elisa de. O Tempo vertical e a dimensão do poético na obra de Clarice Lispector: uma leitura bachelardiana. Discurso, São Paulo, n. 23, p. 177-190, jun. 1994.

PONTIERI, Regina. Clarice Lispector:uma poética do olhar. São Paulo: Ateliê, 2001.

POUILLON, Jean. O tempo no romance. Trad. Heloysa de Lima Dantas. São Paulo: Cultrix; São Paulo: EDUSP, 1974.

REIS, José. Sobre o tempo. Revista de filosofia de Coimbra, Coimbra, v. 5, n. 9, 143-203, 1996.

RICOEUR, Paul. Tempo e narrativa. Trad. Márcia Martinez de Aguiar. São Paulo: Martins Fontes, 2010. v. 2.

SÁ, Olga de. A escritura de Clarice Lispector. Rio de Janeiro: Vozes, 1979. 278 p.

SANTIAGO, Silviano. A aula inaugural de Clarice. Folha de São Paulo, São Paulo, 7 de dez. 1997. p. $5-12$.

Envio: 30/10/2019

Aceite: $08 / 11 / 2019$ 